\title{
Modelo para elaboração de políticas de preservação digital de documentos de arquivo por instituições de ensino superior: o caso da Unesp
}

\author{
Model for the elaboration of policies for the digital preservation of records \\ by higher education institutions: the case of Unesp
}

\section{Modelo para la elaboración de políticas de preservación digital de documentos de archivo por instituciones de educación superior: el caso de la Unesp}

José Carlos Abbud Grácio ${ }^{1, a}$

jose.gracio@unesp.br | https://orcid.org/oooo-0001-7620-1309

\author{
Sonia Troitiño ${ }^{1, b}$ \\ sonia.troitino@unesp.br | https://orcid.org/oooo-0002-7204-3283
}

Telma Campanha de Carvalho Madio ${ }^{1, c}$

telma.madio@unesp.br | https://orcid.org/oooo-0002-7031-2371

José Remo Ferreira Brega ${ }^{2, d}$

remo.brega@unesp.br| https://orcid.org/0000-0002-2275-4722

Maria Blassioli Moraes ${ }^{1, e}$

maria.moraes@unesp.br| https://orcid.org/oooo-0001-5232-7732

\footnotetext{
${ }^{1}$ Universidade Estadual Paulista Júlio de Mesquita Filho, Faculdade de Filosofia e Ciências. Marília, SP, Brasil.

${ }^{2}$ Universidade Estadual Paulista Júlio de Mesquita Filho, Faculdade de Ciências. Bauru, SP, Brasil.

a Doutorado em Ciência da Informação pela Universidade Estadual Paulista Júlio de Mesquita Filho.

${ }^{\text {b }}$ Doutorado em História Social pela Universidade de São Paulo.

c Doutorado em Ciências da Comunicação pela Universidade de São Paulo.

${ }^{d}$ Doutorado em Engenharia de Transportes pela Universidade de São Paulo.

e Mestrado em História Social pela Universidade de São Paulo.
}

\section{RESUMO}

Um dos desafios das mudanças e evoluções das tecnologias de informação e comunicação (TIC) em corporações é a preservação das informações digitais. Entre as corporações com grande geração de informações digitais estão as universidades. Neste artigo, é apresentada uma estratégia para se elaborar uma política de preservação digital no bojo de uma política arquivística direcionada para a manutenção da autenticidade dos documentos de arquivo. O objetivo é expor um modelo para elaboração de políticas de preservação digital de documentos de arquivo por instituições de ensino superior (IES), com os elementos que devem compô-las, a partir da literatura estudada e da política elaborada e aprovada na Universidade Estadual Paulista (Unesp). São apresentados os conceitos relacionados à política arquivística para a preservação digital de documentos de arquivo, sua definição, seus aspectos e elementos. Concluiu-se que o modelo pode ser adaptado para outros objetos digitais, bem como para outras instituições.

Palavras-chave: Preservação digital; Políticas arquivísticas; Política de preservação digital; Autenticidade; Universidade Estadual Paulista - Unesp; Instituição de ensino superior. 


\section{ABSTRACT}

One of the challenges of the changes and evolutions of the information and communication technology (ICT) in corporations is the preservation of digital information. The universities are among the corporations with a large generation of digital information. This article presents a strategy for the elaboration of a digital preservation policy, in the context of an archival policy which is aimed at maintaining the authenticity of archival documents. The objective of this article is to present a model so that the higher education institutions could making policies for the digital preservation of their archival documents, showing the elements that must compose each one, based on the studied literature and on the policy elaborated in Unesp and which was officially approved by that institution. Concepts related to archival policy for the digital preservation of archival documents, their definition, aspects and elements are presented here. It was concluded that the model can be adapted for other digital objects, as well as for other institutions.

Keywords: Digital preservation; Archival policies; Digital preservation policy; Authenticity; Unesp Universidade Estadual Paulista (São Paulo State University); Higher education institution.

\section{RESUMEN}

Uno de los desafíos de los cambios y la evolución de las TIC en las corporaciones es la preservación de informaciones digitales. Entre las corporaciones con una gran generación de información digital se encuentran las universidades. En este artículo, se presenta una estrategia para elaborar una política de preservación digital, en medio de una política de archivo dirigida a mantener la autenticidad de los documentos de archivo. El objetivo del artículo es presentar un modelo para la elaboración de políticas de preservación digital de documentos de archivo por instituciones de enseñanza superior, con los elementos que deben componerlas, basado en la literatura estudiada y en la política desarrollada y aprobada en la Unesp. Se presentan conceptos relacionados con la política de archivo para la preservación digital de documentos de archivo, su definición, aspectos y elementos. Se concluyó que este modelo puede adaptarse para otros objetos digitales, así como para otras instituciones.

Palabras clave: Preservación digital; Políticas de archivo; Política de preservación digital; Autenticidad; Unesp - Universidade Estadual Paulista (Universidad del estado de São Paulo); Institución de Enseñanza Superior.

INFORMAÇÕES DO ARTIGO

Este artigo compõe o Dossiê Preservação Digital.

Contribuição dos autores:

Concepção e desenho do estudo: José Carlos Abbud Gracio, Sônia Troitiño, Telma Campanha de Carvalho Madio, Maria Blassioli Moraes e José Remo Ferreira Brega.

Redação do manuscrito: José Carlos Abbud Gracio, Sônia Troitiño, Telma Campanha de Carvalho Madio, Maria Blassioli Moraes e José Remo Ferreira Brega.

Revisão crítica do conteúdo intelectual: Sônia Troitiño, José Carlos Abbud Gracio, Telma Campanha de Carvalho Madio, Maria Blassioli Moraes e José Remo Ferreira Brega.

Declaração de conflito de interesses: não há.

Fontes de financiamento: não houve.

Considerações éticas: não há.

Agradecimentos/Contribuições adicionais: Agradecemos a Maria Leandra Bizello, Flávia Maria Bastos, Melyssa Claudia Falchi Tomasini, Vagner Roberto de Moraes e Clériston Aparecido Gomes Martinelo que, juntamente com os autores, fizeram parte da Comissão para elaboração da política de preservação digital de documentos de arquivo da Unesp.

Histórico do artigo: submetido: 18 maio 2020 | aceito: 28 jul. 2020 | publicado: 30 set. 2020.

Apresentação anterior: não houve.

Licença CC BY-NC atribuição não comercial. Com essa licença é permitido acessar, baixar (download), copiar, imprimir, compartilhar, reutilizar e distribuir os artigos, desde que para uso não comercial e com a citação da fonte, conferindo os devidos créditos de autoria e menção à Reciis. Nesses casos, nenhuma permissão é necessária por parte dos autores ou dos editores. 


\section{INTRODUÇÃO}

Arquivos de universidades reúnem documentos produzidos e acumulados por instituições de ensino superior (IES) em suas atividades finalísticas de ensino, pesquisa, extensão e cultura, mas também os documentos gerados pelas áreas administrativas, imprescindíveis para que seus objetivos finais institucionais se concretizem.

Segundo Bizelloํㅜ os arquivos de universidades refletem as complexidades das instituições que abarcam desde atividades desenvolvidas pelos docentes junto aos estudantes, que geram documentos referentes à vida acadêmica, até o registro de atividades relacionadas ao desenvolvimento de projetos de pesquisa científica, passando pelo atendimento e demais tarefas relacionadas aos projetos extensionistas realizados por elas junto às comunidades. Disto, compreende-se que a universidade se relaciona com a sociedade, influenciando seu desenvolvimento e mudanças, assim como também está sujeita às influências desta mesma sociedade, na qual está inserida.

Para Boso, Sousa, Cisne e Coradi ${ }^{2}$, apesar da publicação da Lei de Arquivos, na década de 1990, Lei n ${ }^{0}$ 8159/19913 , que dispõe sobre a política nacional de arquivos públicos e privados, na primeira década do século XXI ainda era possível visualizar a ausência de uma legislação voltada aos cuidados e particularidades da gestão dos arquivos das universidades, visando à sua organização, preservação e ao acesso a estes.

As autoras observaram que, apesar de algumas iniciativas como a organização do I Seminário Nacional de Arquivos Universitários, em 1991, promovido pela Universidade Estadual de Campinas (Unicamp), as reflexões e avanços relacionados ao tratamento desses arquivos pareciam não responder às necessidades de pesquisa do público, que poderia se mostrar potencial usuário desse acervo. Naquele momento, os arquivos das IES ainda se apresentavam fragmentados, divididos entre as mais diversas seções de suas instituições de origem, como as de pessoal, reitoria e de cursos, que mantinham seus arquivos correntes para responder à necessidade inicial para a qual foram criados. Ou seja, visualizava-se escassa atenção aos arquivos permanentes das universidades e percebia-se pouca preocupação com a possibilidade de pesquisa acadêmica ou com a preservação da memória institucional.

Somente em 2013, o Ministério da Educação (MEC) publicou a Portaria MEC nº 1224/2013 ${ }^{4}$, instituindo normas para a manutenção e guarda dos acervos acadêmicos das IES pertencentes ao sistema federal de ensino. Embora não abrangesse os arquivos das universidades estaduais, essa portaria assim como outras que a sucederam lançaram destaque às necessidades de respeitar os procedimentos adequados para o tratamento dos arquivos.

Um quesito importante, está na determinação estabelecida por essa portaria para que as instituições apliquem a tabela de temporalidade de documentos das atividades-fim, aprovada pela Portaria AN/MJ no 92, de 23 de setembro de 20115. Essa tabela, instrumento de gestão que define prazos de guarda e destinação final aos documentos, é necessária para compor a política de arquivos e é peça-chave para a conformação do sistema de arquivos de qualquer instituição. Bellotto ${ }^{6}$ bem destacou que o papel principal dos arquivos universitários é: "1 - reunir, processar, conservar e divulgar todos os documentos relativos à administração, histórica e ao funcionamento/desenvolvimento da universidade; 2 - avaliar e descrever estes documentos tornando possível seu acesso, segundo as políticas e procedimentos elaborados especificamente para estes fins. 3 - supervisionar a eliminação, ter o controle da aplicação das tabelas de temporalidade, a fim de que nenhum documento de valor permanente seja destruído.”

As atividades anteriormente elencadas são atribuídas aos arquivos, sejam eles convencionais ou digitais e, para o desenvolvimento da política dos arquivos na Universidade Estadual Paulista 'Júlio de Mesquita Filho' (Unesp), depara-se, segundo observou Bizelloº ${ }^{1}$ com a particularidade de sua estrutura e distribuição geográfica no estado de São Paulo. A centralização administrativa, resultante de sua criação, exigiu a 
reflexão sobre os diferentes procedimentos relacionados à gestão de documentos até então desenvolvidos pelos institutos isolados que os criaram e a sua reorganização.

A Unesp foi criada em 1976, pelo governo do estado de São Paulo por meio da Lei Estadual n ${ }^{\circ}$ 952, de 30 de janeiro de 1976, a partir da reunião de 13 Institutos isolados de ensino superior presentes em cidades do interior do estado de São Paulo. Posteriormente, outras faculdades foram criadas e incorporadas. Atualmente, a Universidade possui 34 faculdades, além de institutos e da reitoria distribuídos em 24 cidades do estado de São Paulo, conforme apresentado na Figura 1. Cada uma das unidades possui uma Seção Técnica de Comunicações que responde pela execução da gestão documental da sua unidade, segundo a Portaria Unesp 469/2012 e seguem as políticas de arquivo definidas pela Comissão de Avaliação de Documentos e Acesso (CADA) da Unesp.

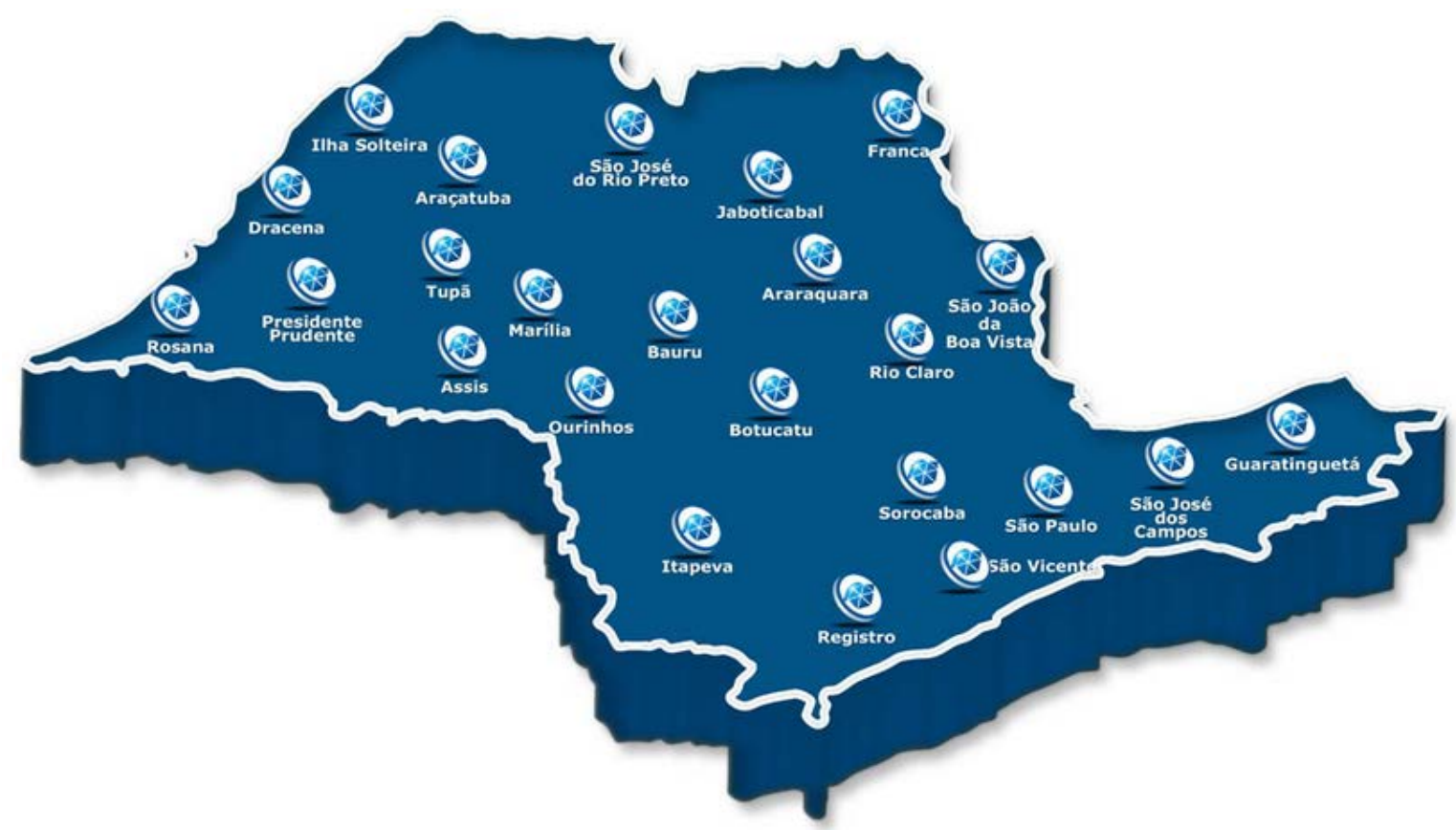

Figura 1 - Unidades da Unesp

Fonte: Unesp (2019).

Esse cenário traz para a Universidade o desafio de manter documentos e informações convencionais, digitalizados e nato-digitais, preservados e acessíveis. É preciso considerar permanentemente as questões legais que permeiam os avanços engendrados pelas novas Tecnologias de Informação e Comunicação (TIC) disponíveis, diante dos desafios que elas nos apresentam, tais como o crescimento da produção de informações digitais; a obsolescência de hardwares e de softwares; as mudanças no formato dos arquivos e das mídias de armazenamento; a busca e recuperação de documentos e informações digitais; o custo elevado das novas tecnologias; a necessidade de recursos humanos e tecnológicos; assim como a capacidade de assimilação dessas mudanças, incluindo as relativas à cultura organizacional e aos avanços científicos.

Em decorrência da implantação das políticas públicas de arquivos elaboradas pelo governo do estado de São Paulo e pelo governo federal, a Unesp aprovou e publicou, em 2015, o Plano de classificação e a tabela de temporalidade de Documentos da Unesp: Atividades-Meio ${ }^{8}$ e, em 2018, foi publicado o Plano de classificação e a tabela de temporalidade de documentos da Unesp: atividades-fim ${ }^{9}$. No final da etapa de construção destes instrumentos, a Comissão de Avaliação de Documentos e Acesso da Unesp - CADA elaborou o livro Panorama da Gestão Documental na Unesp ${ }^{10}$, obra que reuniu artigos que abordam aspectos da trajetória da Universidade para a consolidação de suas políticas e do sistema de arquivos.

Para a gestão dos documentos e das informações digitais, a Unesp determinou mediante a Portaria Unesp $\mathrm{n}^{0}$ 81/2016 ${ }^{11}$ a formulação de uma política de preservação digital que definisse diretrizes, objetivando 
manter a integridade, a autenticidade e o acesso aos documentos e informações digitais. Como antecedente, as primeiras discussões sobre o tema foram realizadas em 2015, quando teve início um debate a respeito de quais documentos digitais a política deveria atender. Definiu-se que a política deveria abranger, inicialmente, a preservação digital dos documentos de arquivo, uma vez que, a comissão criada para elaborar a política entendeu que as particularidades desses documentos, que são únicos, e suas diferenças frente aos documentos de biblioteca e de museus, exigiam uma política voltada somente aos documentos de arquivo.

Dessa forma, o objetivo do artigo é apresentar um modelo para elaboração de políticas de preservação digital de documentos de arquivo por IES, com os elementos que devem compô-las, a partir da literatura estudada e da experiência da Unesp na elaboração de sua política. Esse modelo divide-se, além da Introdução e das Referências, em cinco seções: a primeira apresenta os conceitos relacionados à política arquivística para a preservação de documentos de arquivo; na segunda, discute-se a definição de preservação digital e seus aspectos, e os elementos para a elaboração de uma política de preservação digital; na terceira, relata-se como a política da Unesp foi desenvolvida e quais referências e experiências foram utilizadas; na quarta, apresenta-se o modelo proposto e os elementos que compõem a política; por fim, na quinta são apresentadas as considerações finais.

\section{POLÍTICA ARQUIVÍSTICA PARA PRESERVAÇÃO DE DOCUMENTOS DE ARQUIVO}

Política arquivística pode ser entendida como o conjunto articulado de princípios e diretrizes adotado para a criação, gerenciamento, preservação de documentos de arquivo e para acesso a eles, utilizado por uma organização para regrar o seu sistema de informação. Relaciona-se à racionalização administrativa, quando consideramos a capacidade que tem uma entidade de se organizar e prever, à luz da missão institucional que lhe compete, o registro de seus atos, tanto com finalidade instrumental, quanto memorialística, assim como a preservação destes em larga escala de tempo, conforme destinação estabelecida por meio do estudo da temporalidade dos documentos.

De modo bastante didático, Cruz Mundet ${ }^{12}$ definiu política arquivística como sendo o: "Conjunto de orientaciones o directrices para producir y gestionar documentos auténticos, fiables y utilizables, capaces de sostener las funciones y actividades de las organizaciones y de los individuos durante tanto tiempo como sea necesario, y de servir como memoria y fuente para la historia. Incluye el establecimiento de un marco normativo, así como la dotación de los medios materiales, y humanos necesarios para su desarrollo. La política archivística debe ser adoptada al más alto nivel de decisión y promulgada, comunicada e implementada en todos los niveles de una organización."

Dessa forma, é possível pensar na política arquivística como aquela destinada a formular objetivos e propor meios apropriados para a sua execução, tendo no horizonte a garantia de direitos coletivos e individuais, do cumprimento das necessidades burocráticas das instituições envolvidas, pari passu aos interesses de pesquisa relacionados ${ }^{13}$. Abordagem similar à de Sousa ${ }^{14}$, ao defender que os objetivos de uma política pública de arquivo devem considerar, além do apoio administrativo, memorialístico e científico, o direito do cidadão à informação.

Mark Driskill ${ }^{15}$ afirma que a política arquivística não é uma política específica, única, mas fundamentalmente uma compilação de políticas e instruções inter-relacionadas, que se conectam para gerir a instituição. Configura-se como um conjunto de regras e procedimentos, utilizados pelas organizações para gerir suas operações. Por sua vez, Troitiño $0^{16}$ detalha, em Arquivos, que a política pode atingir diversos âmbitos de sua atuação. Desse modo, é aconselhável que as instituições de resguardo do patrimônio documental, fundamentem suas ações em políticas por elas estabelecidas, tais como as relativas à conservação, segurança, formação de acervo, acesso ou qualquer outra que oriente protocolos de trabalho.

Seguindo esse viés, Fujita e Troitiño ${ }^{17}$ defendem que a adoção de uma política arquivística tem extraordinária relevância dentro de uma instituição, especialmente quando se trata de documentação 
digital, pois esta implica em articulação com outras políticas específicas relacionadas, como as políticas de preservação digital, recuperação e indexação de documentos. Por sua vez, Fuster Ruiz ${ }^{18}$ acredita que qualquer política arquivística deve ser estabelecida a partir da preservação e uso dos documentos de arquivo, especialmente quando se considera a migração de suportes com a finalidade de preservação.

Sem a adoção de protocolos bem definidos e divulgados, a segurança do sistema e a transparência pública da informação podem vir a ser questionados, ocasionando contestações e falta de confiança no fornecimento de documentos e dados. Segundo Duranti ${ }^{19}$, a defesa de um documento inativo, ou seja, de sua autenticidade, é provida por três fatores essenciais: transparência na preservação dos documentos, segurança e estabilidade.

Diante disto, é preciso considerar que o desenvolvimento de uma política de preservação digital de documentos, no cerne de uma política arquivística institucional, agrega valor ao conferir confiabilidade e fidedignidade tanto aos documentos que preserva, quanto ao sistema de informação do qual fazem parte, no esteio da autenticidade documental.

\section{POLÍTICA DE PRESERVAÇÃO DIGITAL}

A preservação digital pode ser entendida como "os processos de gestão envolvidos na administração das atividades necessárias para garantir que um objeto digital possa ser acessado e utilizado no futuro, a partir das TIC existentes na época e com garantias de sua autenticidade e integridade." ${ }^{20}$

Para Ferreira ${ }^{21}$ a preservação digital "consiste na capacidade de garantir que a informação digital permanece acessível e com qualidades de autenticidade suficientes para que possa ser interpretada no futuro recorrendo a uma plataforma tecnológica diferente da utilizada no momento da sua criação."

Para Arellano ${ }^{22}$, a preservação digital "[...] compreende mecanismos que permitem o armazenamento em repositórios de dados digitais que garantam a perenidade dos seus conteúdos [...]”, e integra os requisitos da preservação física, lógica e intelectual dos objetos digitais.

Nesse sentido, a preservação digital envolve diversas áreas e diversos profissionais de uma instituição, que devem estar envolvidos nos processos de gestão para garantir a preservação e o acesso aos objetos digitais.

Os documentos de arquivo são objetos digitais que devem ser preservados e possuem suas próprias especificidades, conforme apresentado nas seções anteriores. A preservação digital desses documentos deve levar em consideração todo seu ciclo de vida, que se refere, conforme definido pelo e-Arq Brasil"23 "a sucessivas etapas pelas quais passam os documentos: produção, tramitação, uso, avaliação, arquivamento e destinação (guarda permanente ou eliminação).”

O ciclo de vida está relacionado com a cadeia de custódia, que pode ser definida como "o ambiente no qual perpassa o ciclo de vida dos documentos. Em outras palavras, ela define quem é o responsável por aplicar os princípios e as funções arquivísticas à documentação.”24

Flores, Rocco e Santos ${ }^{24}$ apontam a necessidade da manutenção de uma cadeia de custódia digital ininterrupta para se gerenciar os documentos de arquivo ao longo do seu ciclo de vida e que essa cadeia é composta por três ambientes interoperáveis: gestão de documentos; preservação; e acesso, descrição arquivística e difusão (plataforma de acesso).

Os autores ressaltam que "a manutenção então desta linha ininterrupta digital, desta cadeia de custódia digital, para os documentos arquivísticos, neste ambiente, pressupõe que as ferramentas digitais e os ambientes de gestão, de preservação e de acesso contemplem os requisitos, as normas, os padrões de metadados." ${ }^{24}$

A política de preservação digital deve garantir a autenticidade dos documentos de arquivo nos ambientes de gestão e preservação, condição fundamental para garantir a confiabilidade e o acesso aos documentos disponíveis no ambiente de gestão e nas plataformas de acesso. Dessa forma, a elaboração e aprovação de 
uma política de preservação digital é fundamental para definir os objetivos e diretrizes necessários para a implantação dos processos de gestão envolvidos.

Uma política de preservação digital pode ser compreendida como o documento que define os objetivos e diretrizes de uma instituição para a implantação de um programa de preservação de seus registros e objetos digitais. Essa política deve estar alinhada com os objetivos e com as outras políticas institucionais em vigor e ser revista ao longo do tempo, abrangendo todos os elementos relacionados à preservação digital, inclusive aqueles relacionadas à cultura organizacional e as mudanças nas TIC. Dessa forma, constitui um compromisso institucional para garantir o acesso e a integridade de um acervo, como no caso dos documentos de arquivo digitais.

O glossário do projeto Scalable Preservation Environments (SCAPE) ${ }^{25}$ aponta que uma política de preservação "deve fornecer os mecanismos para documentar e comunicar aspectos importantes de relevância, em particular fatores e restrições e os objetivos e metas motivados por eles. Eles devem apoiar as atividades de uma organização no que diz respeito à manutenção e preservação de uma coleção digital."

Em 2007, uma parceria estabelecida para a formação de profissionais de arquivo, entre o Conselho Internacional de Arquivos (ICA - International Council on Archives) e o International Research on Permanent Authentic Records in Electronic Systems (Interpares), em sua $3^{\text {a }}$ fase de desenvolvimento (2007-2012), criou um programa para o desenvolvimento de materiais educativos a fim de apoiar ações de preservação digital em instituições e organizações. Essa parceria, deu origem a oito módulos de capacitação sob o título, em inglês, Digital Records Pathways: Topics in Digital Preservation ${ }^{26}$. Entre diversos outros pontos, o programa orienta para o estabelecimento dos requisitos fundamentais a serem atendidos para garantir uma eficiente implementação de política de preservação digital. São eles: "Documentos de arquivo digital devem ser gerados e mantidos autênticos e confiáveis; Documentos de arquivo digital devem continuar sendo utilizáveis ao longo do tempo; As práticas de gerenciamento de documentos devem aderir a padrões e boas práticas relevantes; Documentos de arquivo digital devem ser mantidos e preservados de acordo com todos os requisitos regulamentares relevantes; e Documentos de arquivo identificados para preservação a longo prazo provavelmente serão preservados." ${ }^{26}$

Arellano e Andrade ${ }^{27}$ afirmam que "[...] a metodologia de organização e descrição dos objetos digitais deve observar a natureza da informação a ser preservada, isso é premissa para que a política de preservação digital seja estruturada de acordo com o acervo". Assim, a política deve contemplar esses requisitos para garantir o acesso aos objetos digitais preservados, incluindo, em seu cerne, elementos de gestão e organização.

Para garantir a autenticidade e o acesso a longo prazo dos objetos digitais a serem preservados, a política de preservação digital deve abranger todos os elementos da preservação digital, levando em consideração as mudanças e avanços nas TIC e na cultura organizacional, conforme apontado na Figura 2.

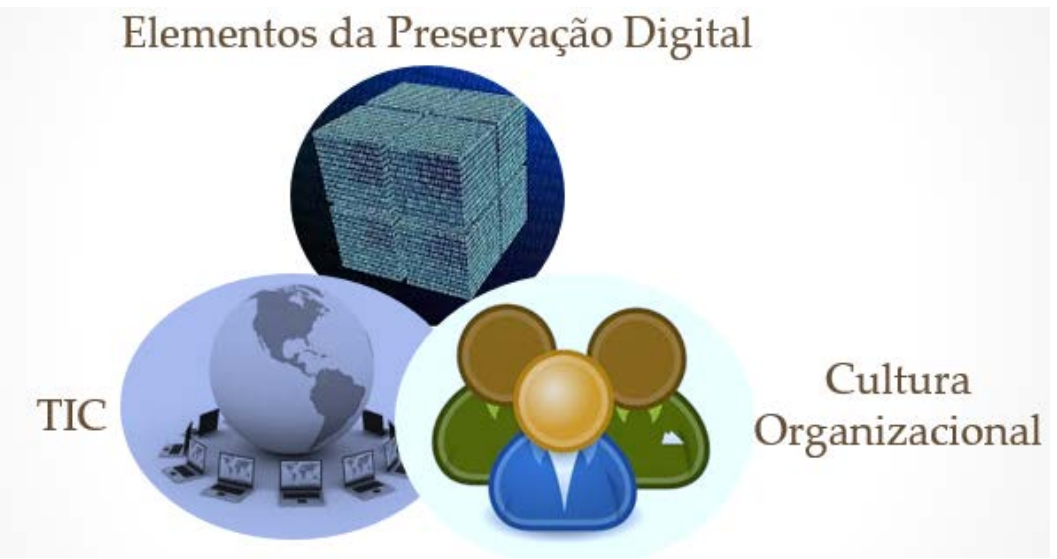

Figura 2 - Política de preservação digital

Fonte: Adaptação de Grácio $(2012)^{20}$. 
A mudança na cultura organizacional ocorre, pois a preservação digital envolve todas as instâncias da instituição, desde o criador do objeto digital até os responsáveis por ela. Os processos de trabalho envolvidos na preservação digital alteram a rotina e as atividades das pessoas. É necessário que todos os envolvidos na instituição entendam que a necessidade dessas novas atividades tem o objetivo de garantir o acesso a esses objetos digitais e sua autenticidade.

Os elementos para preservação digital podem ser definidos em três grupos: organizacional, legal e técnico, conforme Figura 3.

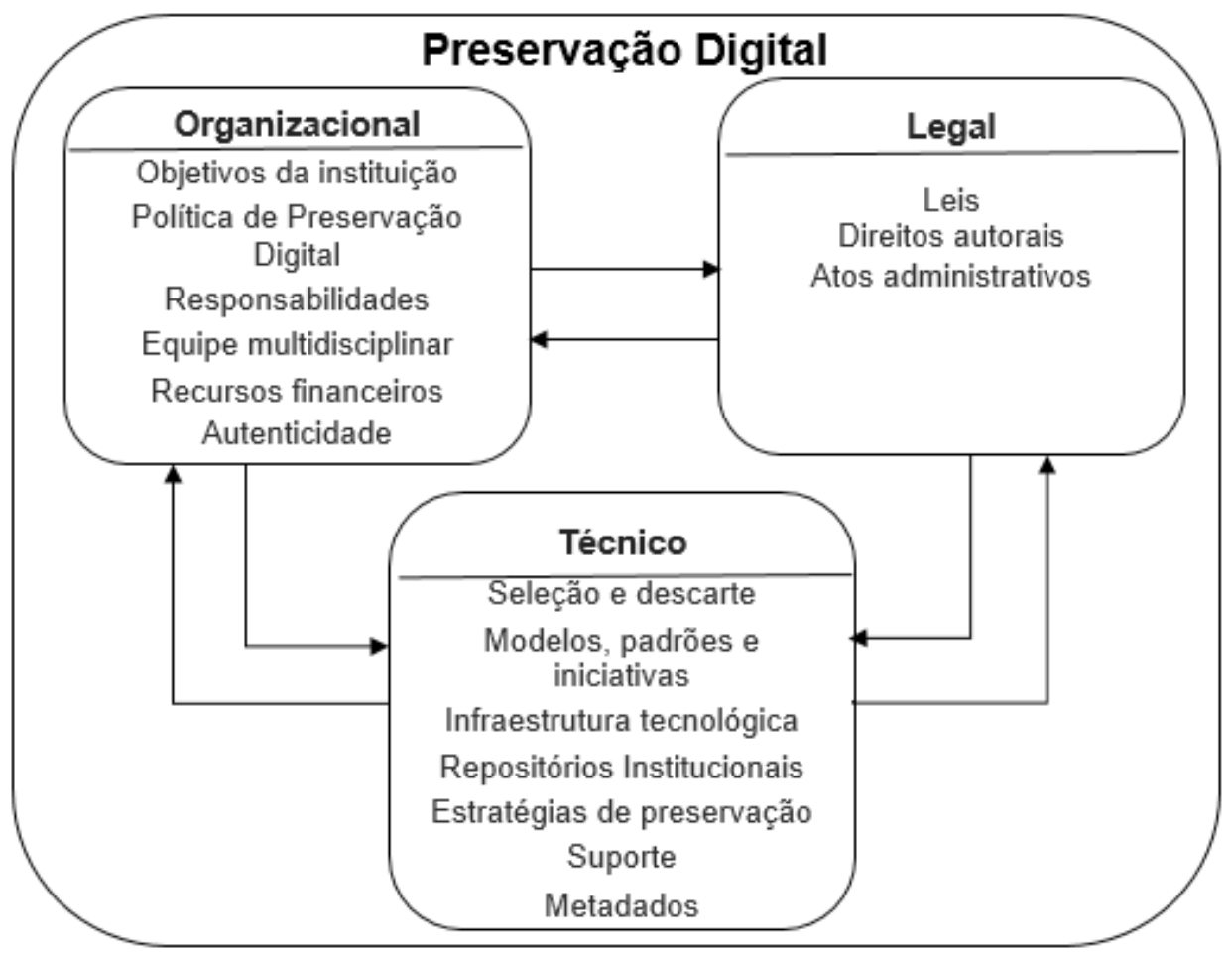

Figura 3 - Elementos para preservação digital Fonte: Adaptação de Grácio $(2012)^{20}$.

Os elementos organizacionais, destacados na Figura 3, são aqueles relativos às atividades de gestão da instituição e estão diretamente relacionados aos objetivos da preservação digital; à comunidade e às pessoas envolvidas nas atividades; à definição de suas responsabilidades; à montagem de uma equipe que realize a gestão dos processos envolvidos; à alocação de recursos financeiros; à responsabilidade de garantir a autenticidade; e à definição de políticas de preservação digital. Conforme Grácioº ${ }^{20}$, esses elementos "buscam dar sustentação organizacional com o objetivo de dar continuidade às atividades de preservação digital, independente das mudanças que possam ocorrer na gestão da instituição, nos recursos financeiros disponíveis ou nas políticas."

Os elementos legais estão relacionados a questões legais, a direitos autorais e a leis que regem os objetos digitais, sejam essas normativas internacionais ou nacionais, que devem ser complementadas por atos internos que, nesse caso, devem ser registradas por atos administrativos, como normas e portarias. Dessa forma, pode-se garantir a legalidade dos processos de preservação digital para a instituição e para o criador do objeto digital.

Elementos técnicos, por sua vez, estão relacionados às questões técnicas envolvidas nas atividades de informática, biblioteconomia, arquivologia e outras correlacionadas. Envolvem questões como: a seleção do que preservar e do que descartar; a utilização de modelos e padrões; participação em iniciativas nacionais e internacionais que permitam a troca de experiência e conhecimento entre instituições; a montagem 
da infraestrutura tecnológica para preservação e acesso aos objetos digitais preservados; a aplicação das estratégias adequadas de preservação digital; o uso do suporte adequado; e a representação por metadados.

Nesse sentido, a utilização de modelos e padrões é fundamental para padronizar os processos envolvidos na preservação digital e permitir a interoperabilidade de informações, quando necessária. O modelo de referência para as soluções de preservação digital que tem sido adotado e citado na literatura é o Open Archival Information System (OAIS), uma norma BS ISO 14721 de 2012 que está, atualmente, em sua $2^{\text {a }}$ versão. Uma versão da proposta OAIS redigida em português foi publicada em 2007 como norma ABNT NBR 15472:2007 com o nome de Sistemas Espaciais de Dados e Informações - Modelo de referência para um Sistema Aberto de Arquivamento de Informações (SAAI) ${ }^{28}$. Por ser um esquema conceitual, define e modela o que é preciso para desenvolver um sistema de armazenamento, preservação e acesso da informação digital, sendo amplamente utilizado no desenvolvimento de sistemas de preservação digital.

A Unesp, para elaboração da sua política de preservação digital para documentos de arquivo, embasouse na literatura exposta nesta seção com o objetivo de dar sustentação teórica e propiciar reflexão sobre as práticas universitárias em vigor.

\section{ESTRATÉGIAS PARA O DESENVOLVIMENTO DE UMA POLÍTICA DE PRESERVAÇÃO DIGITAL DE DOCUMENTOS DE ARQUIVO - O CASO DA UNESP}

Para um desenvolvimento coeso e eficiente na adoção de documentos digitais em suas rotinas burocráticas, a Unesp decidiu, em 2016, criar um grupo responsável pela elaboração de uma política de preservação digital para documentos de arquivo, a ser adotada por todos os setores da universidade. Dessa forma, a Portaria Unesp $n^{\circ} 81$, de $1^{\circ}$ de março de 2016, "instituiu a Comissão para fins de elaboração da Política de preservação digital de documentos de arquivo" ${ }^{11}$, ligada diretamente ao gabinete do reitor.

A portaria apresenta em seu primeiro artigo as finalidades primordiais da mencionada comissão: "I - estudar e elaborar a Política de preservação digital de documentos de arquivo da Unesp; II - definir diretrizes e procedimentos com o objetivo de garantir a autenticidade, integridade e acesso aos documentos por um longo período de tempo, e a manutenção do seu valor jurídico, histórico e diplomático;

III - definir diretrizes para a criação de repositório seguro e confiável para os documentos arquivísticos nato digitais e digitalizados." ${ }^{11}$

Para a concretização desses objetivos e, por englobar diversos setores da universidade - Administrativo, Ensino, Pesquisa e Extensão -, os comissionados selecionados representavam as mais diferentes áreas: arquivologia, biblioteconomia, informática, direito, ciência da informação, gestão da universidade, das Seções Técnicas de Comunicação da Unesp (STCOM), além de um especialista em preservação digital, formando, assim, uma equipe de matriz multidisciplinar. O trabalho da equipe foi realizado integrado com órgãos cruciais da Unesp, como a Comissão de Avaliação de Documentos e Acesso (CADA), a Assessoria Jurídica (AJ) e a Coordenadoria de Tecnologia da Informação (CTInf), responsável pela gestão da área de informática da Unesp.

Inicialmente foi necessário que todos os membros da comissão tivessem o entendimento dos conceitos envolvidos na gestão arquivística de documentos e na preservação digital. As reuniões aconteciam uma vez por mês e os debates, entre os comissionados, foram constantes e intensos, mas proveitosos para assimilação dos fundamentos essenciais para o entendimento do objeto a ser tratado pela política de preservação digital, como os conceitos de objeto digital, documento digital e documento de arquivo, de uma forma precisa e coesa.

A aproximação feita aos temas foi iniciada com o estudo sobre: 1) o Plano de Classificação e a Tabela de Temporalidade de Documentos de Atividades-Meio da Unesp ${ }^{8}$, determinando prazos de guarda e destinação final dos documentos digitais e não digitais a fim de compreender-se a diversidade documental 
da universidade; 2) a Lei ${ }^{\circ} 12.682$, de 09 de julho de $2012^{29}$, que dispõe sobre a elaboração e o arquivamento de documentos em meio eletromagnéticos, determinando a legalidade na criação dos suportes documentais; 3) as várias recomendações do Conselho Nacional de Arquivos - Conarq, especialmente a Resolução nº 37, de 19 de dezembro de $2012^{30}$, que apresenta as "Diretrizes para a presunção de autenticidade de documentos arquivísticos", e a Resolução $\mathrm{n}^{\circ}$ 43, de 04 de setembro de $2015^{31}$, que "estabelece diretrizes para a implementação de repositórios digitais confiáveis para a transferência e recolhimento de documentos arquivísticos digitais para instituições arquivísticas dos órgãos e entidades integrantes do Sistema Nacional de Arquivos - Sinar.”; e 4) estudos sobre a Norma ABNT NBR 15472:200 $7^{28}$ (ISO 14721:2012).

Recorreu-se a diversos teóricos para o embasamento das discussões, mas aqui destaca-se o uso constante dos trabalhos de Arellano ${ }^{22}$; Arellano e Andrade ${ }^{27}$; Arellano e Oliveira ${ }^{32}$; Baggio e Flores ${ }^{33} ;$ Ferreira $^{21}$; Santos e Flores ${ }^{34}$; Flores ${ }^{35}$; Flores, Rocco e Santos²4; Sayão ${ }^{36}$; e Grácio ${ }^{20}$.

Ao mesmo tempo, buscavam-se experiências que estudavam e divulgavam procedimentos sobre esse tipo de implementação. Tomou-se por base projetos como: o Projeto InterPARES - The International Researchon Permanent Authentic Records in Electronic Systems, coordenado pela Profa. Dra. Luciana Duranti da Universidade de British Columbia, Canadá, que, desde 1999, vem desenvolvendo conhecimento teórico-metodológico para a preservação de longo prazo de documentos arquivísticos digitais autênticos e

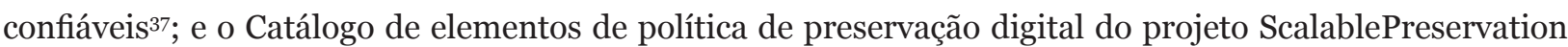
Environments-SCAPE ${ }^{25}$.

Outras interações importantes foram as estabelecidas com a Rede Brasileira de Serviços de Preservação Digital - Rede Cariniana ${ }^{38}$ : projeto do Instituto Brasileiro de Informação em Ciência e Tecnologia - Ibict com outras universidades, que visava a parcerias nos trabalhos de preservação digital de documentos eletrônicos brasileiros, com o objetivo de garantir seu acesso contínuo a longo prazo; e com o Grupo de Trabalho de Documentos Arquivísticos Eletrônicos da Universidade Estadual de Campinas (Unicamp). Esses contatos, permitiram maior aproximação com profissionais teóricos e técnicos da preservação digital. Percebeu-se que, nessa época, eram ainda incipientes as iniciativas e os projetos relacionados à preservação digital ${ }^{39}$, bem como a divulgação das políticas existentes, sendo poucas as instituições nacionais e internacionais que já haviam publicado suas políticas de preservação digital ${ }^{40}$. Contudo, as políticas de preservação digital ativas encontradas foram levantadas para análise, a fim de compreensão e definição da estrutura de uma política e seus elementos essenciais. Entre elas, destacam-se: Universidade Estadual de Campinas (Unicamp) ${ }^{41}$; Câmara dos Deputados ${ }^{42}$; Arquivo Nacional ${ }^{43}$; State Library of Queensland ${ }^{44}$; Parliament de Londres ${ }^{45}$; University of Massachusetts Amherst46; National Library of Australia-NLA47; Yale University Library ${ }^{48}$; e a política proposta por Silva Junior e Borges ${ }^{49}$.

Com olhares múltiplos e embasados por essas referências, chegou-se à decisão de se adotar a proposta elaborada por Grácio $^{20}$ para desenvolver uma política de preservação digital para a Unesp. Assim, amparados em literatura especializada e na experiência da Unesp, apresentamos a seguir um modelo para que instituições análogas possam elaborar suas políticas de preservação digital dos documentos de arquivo em formato digital.

\section{MODELO PARA A ELABORAÇÃO DE UMA POLÍTICA DE PRESERVAÇÃO DIGITAL DOS DOCUMENTOS DE ARQUIVO DE UMA IES}

O modelo para a elaboração de uma política de preservação digital dos documentos de arquivo de uma IES é descrito na Figura 4 e inclui dez fases de desenvolvimento. Esse modelo foi desenvolvido a partir da elaboração da política da Unesp: 
1. Definir o objetivo da política

2. Constituir uma equipe multidisciplinar

3. Entender o que envolve a Preservação Digital

4. Analisar políticas existentes

\section{Buscar parcerias com outras instituições}

6. Identificar os elementos necessários

\section{Elaborar um rascunho}

8. Finalizar o documento

9. Discutir o documento com as áreas interessadas

\section{Aprovar a política institucionalmente}

Figura 4 - Modelo para a Elaboração de Política de Preservação Digital de uma IES Fonte: Elaboração própria (2020).

A seguir estão detalhadas cada uma das fases do modelo para a elaboração de uma política de preservação digital de documentos:

1. Definir o objetivo da política

As IES devem definir quais objetos digitais devem ser preservados (dados de pesquisa, produção acadêmica, tese, dissertações, documentos de arquivo e outros), a partir de necessidades legais e culturais, e quais os objetivos que pretende atingir. A partir dessa definição e desse compromisso, inicia-se a elaboração da política de preservação digital.

2. Constituir uma equipe multidisciplinar

Por englobar diversos setores da IES, como administrativo, ensino, pesquisa e extensão, é necessária para a elaboração da política, uma equipe multidisciplinar com representantes das áreas envolvidas, tais como arquivologia, biblioteconomia, informática, direito, ciência da informação, gestão da instituição e outras. A equipe será responsável pela elaboração da política e deverá ser formalizada por meio de ato administrativo que definirá sua composição e suas atribuições.

3. Entender o que envolve a preservação digital

A primeira atividade da equipe multidisciplinar deve ser chegar a um entendimento homogêneo sobre os conceitos envolvidos na gestão arquivística de documentos e na preservação digital. Essa atividade é fundamental para que todos possam entender as questões, os elementos e os termos utilizados para a elaboração da política.

4. Analisar políticas existentes

A análise prévia de outras políticas existentes permite a equipe multidisciplinar agilizar o processo de elaboração da política e se revela altamente vantajosa, pois propicia o levantamento de modelos e elementos que podem ser utilizados e/ou adaptados para a realidade da instituição.

5. Buscar parcerias com outras instituições

Outra atividade que auxilia a elaboração é a busca de parcerias com outras instituições que atuem na área de preservação digital. Essas parcerias permitem a troca de conhecimento e experiências, além de colocar a equipe multidisciplinar em contato com outras instituições e especialistas da área. No Brasil, uma instituição que tem atuado na área de preservação digital é a Rede Cariniana, que "tem como objetivo salvaguardar os registros da ciência, tecnologia e do patrimônio cultural do Brasil. ” A rede possui parceria com instituições envolvidas na preservação digital que trocam informações, experiências, serviços e soluções. ${ }^{38}$ 
6. Identificar os elementos necessários

Para elaborar a estrutura da política é necessário definir quais elementos deverão estar presentes no documento. Eles devem ser definidos a partir da literatura existente, das políticas existentes, das parcerias estabelecidas e das especificidades da IES.

7. Elaborar um rascunho

A partir da definição dos elementos que irão compor a política define-se a estrutura do documento e como eles estarão dispostos. A partir dessa estrutura é possível elaborar um rascunho do documento. Essa atividade deve ser distribuída entre os membros da equipe multidisciplinar de acordo com o conhecimento e a especialidade de cada um.

8. Finalizar o documento

A partir da conclusão da etapa de elaboração do rascunho, a equipe multidisciplinar deve discutir e fazer a redação final do documento a ser apresentado às áreas interessadas.

9. Discutir o documento com as áreas interessadas

A minuta da Política de Preservação Digital de Documentos deve ser apresentada, discutida e ajustada conforme as demandas observadas pelas áreas envolvidas. Após essa fase, o documento pode ser concluído e apresentado às instâncias superiores institucionais para sua aprovação e implementação.

10. Aprovar a política institucionalmente

A política elaborada deve ser encaminhada e aprovada pelas instâncias superiores da IES, como o Conselho Universitário. Isso dá uma segurança na continuidade dos processos, pois a preservação digital é um processo contínuo e será parte permanente das atividades institucionais.

No Quadro 1 apresenta-se um modelo de documento com os elementos de uma política que estão sujeitos a alterações e que também proporcionam às instituições criar seu próprio conjunto de elementos.

\section{Quadro 1 - Modelo de documento com os elementos da Política de Preservação Digital de Documentos de Arquivo de uma IES}

\begin{tabular}{|c|c|}
\hline Elemento & Conteúdo \\
\hline Contexto & $\begin{array}{l}\text { Apresenta o contexto da preservação digital na sociedade e na IES, diante das } \\
\text { mudanças e dos avanços nas TIC. }\end{array}$ \\
\hline Compromisso institucional & $\begin{array}{l}\text { Assegura que IES irá se responsabilizar pela preservação dos documentos de arquivo } \\
\text { em formato digital sob sua responsabilidade, garantindo sua autenticidade, integridade, } \\
\text { o acesso a longo prazo e a continuidade dos processos envolvidos. }\end{array}$ \\
\hline Objetivos & Aponta os objetivos da política. \\
\hline Diretrizes & Apresenta as diretrizes baseadas no compromisso institucional e nos objetivos. \\
\hline Cultura organizacional & $\begin{array}{l}\text { Sinaliza que a cultura organizacional será afetada pela política e que sua } \\
\text { implementação dependerá do fator humano, ou seja, de um ambiente informacional } \\
\text { adequado às novas práticas e tecnologias utilizadas. }\end{array}$ \\
\hline $\begin{array}{l}\text { Tecnologias de Informação } \\
\text { e Comunicação }\end{array}$ & $\begin{array}{l}\text { Determina os recursos tecnológicos e pessoal técnico capacitado para a gestão dos } \\
\text { procedimentos diante das mudanças e avanços nas TIC. }\end{array}$ \\
\hline Fundamentos legais & $\begin{array}{l}\text { Aponta as principais normas (leis, decretos, resoluções, portarias e outros) nas quais a } \\
\text { política se apoia e a necessidade de adequação, quando necessário. }\end{array}$ \\
\hline Procedimentos & Define os procedimentos e a estrutura para implementação da política. \\
\hline Responsabilidades & $\begin{array}{l}\text { Determina os responsáveis pela preservação digital dos documentos de arquivo e suas } \\
\text { atribuições. }\end{array}$ \\
\hline Recursos financeiros & $\begin{array}{l}\text { Prevê a necessidade da definição de estratégias de investimentos permanentes nos } \\
\text { processos envolvidos na preservação digital, com objetivo de atender as demandas } \\
\text { como capacitação profissional, estrutura organizacional, infraestrutura tecnológica e } \\
\text { outras. }\end{array}$ \\
\hline Atos administrativos & $\begin{array}{l}\text { Indica os atos administrativos que deverão ser criados para complementar a legislação } \\
\text { e normatizar os processos. }\end{array}$ \\
\hline
\end{tabular}


conclusão

\begin{tabular}{|c|c|}
\hline Elemento & Conteúdo \\
\hline Direitos autorais & $\begin{array}{l}\text { Alerta para as estratégias de preservação digital, que deverão resguardar os direitos } \\
\text { autorais, conforme legislação em vigor. }\end{array}$ \\
\hline $\begin{array}{l}\text { Avaliação, seleção e } \\
\text { eliminação }\end{array}$ & $\begin{array}{l}\text { Estabelece que os procedimentos de avaliação, seleção e eliminação dos documentos } \\
\text { de arquivo em formato digital deverão seguir a política de gestão de documentos, } \\
\text { respeitando os critérios dos planos de classificação e a tabela de temporalidade em } \\
\text { vigor na instituição. }\end{array}$ \\
\hline $\begin{array}{l}\text { Padrões e modelos de } \\
\text { referência }\end{array}$ & $\begin{array}{l}\text { Prevê a utilização de padrões e modelos de referência aprovados e utilizados por outras } \\
\text { IES }\end{array}$ \\
\hline Metadados & $\begin{array}{l}\text { Define os padrões de metadados de preservação digital a serem adotados e utilizados, } \\
\text { que deverão acompanhar todo o ciclo de vida dos documentos de arquivo digital, } \\
\text { registrando as estratégias aplicadas e as mudanças ocorridas. }\end{array}$ \\
\hline Infraestrutura tecnológica & $\begin{array}{l}\text { Define a necessidade de infraestrutura tecnológica para preservação e acesso aos } \\
\text { documentos de arquivo preservados. }\end{array}$ \\
\hline Repositórios digitais & $\begin{array}{l}\text { Indica a importância e a necessidade da implementação de repositórios arquivísticos } \\
\text { digitais confiáveis que sigam as normas estabelecidas pelo Conselho Nacional de } \\
\text { Arquivos (Conarq), por meio da sua Resolução n } 43 \text {, de 04/09/201531. Dessa forma, } \\
\text { os procedimentos de preservação digital estarão em conformidade com o modelo de } \\
\text { referência OAIS. }\end{array}$ \\
\hline $\begin{array}{l}\text { Estratégias de preservação } \\
\text { digital }\end{array}$ & $\begin{array}{l}\text { Estabelece a necessidade de se implementar estratégias de preservação digital } \\
\text { conforme as características e especificidades de cada tipo de documento, avaliando } \\
\text { periodicamente as tecnologias existentes no momento para determinar qual a melhor } \\
\text { estratégia a ser implementada. }\end{array}$ \\
\hline Suporte & $\begin{array}{l}\text { Aponta a utilização de suportes que atendam as infraestruturas de preservação e de } \\
\text { acesso. }\end{array}$ \\
\hline $\begin{array}{l}\text { Modelo processual de } \\
\text { preservação digital }\end{array}$ & $\begin{array}{l}\text { Sinaliza a necessidade de um modelo processual de preservação digital composto de } \\
\text { processos que definam as atividades envolvidas na preservação dos documentos de } \\
\text { arquivo em formato digital. }\end{array}$ \\
\hline Iniciativas & $\begin{array}{l}\text { Indica a necessidade de buscar parcerias com outras instituições com o objetivo de } \\
\text { avançar na implantação dos processos necessários, mediante a troca de experiências e } \\
\text { de soluções. }\end{array}$ \\
\hline Bibliografia consultada & Apresenta o embasamento teórico e prático utilizado para a elaboração da política. \\
\hline Glossário & $\begin{array}{l}\text { Apresenta os termos e conceitos adotados, não só para a elaboração da política, mas } \\
\text { também para a sua efetiva implementação. }\end{array}$ \\
\hline
\end{tabular}

Fonte: Elaboração própria (2020).

A partir da aprovação, a IES deverá iniciar os processos para implantação da política, sendo que uma das primeiras atividades deve ser a criação de uma comissão, com uma composição semelhante ao perfil de uma equipe multidisciplinar, para a gestão dos processos envolvidos na implantação do programa de preservação digital dos documentos de arquivo.

\section{CONSIDERAÇÕES FINAIS}

Com os resultados apresentados, amparados na literatura especializada e na experiência e aplicação na Unesp, entende-se que o modelo proposto atende os requisitos necessários para uma IES elaborar sua política de preservação digital para documentos de arquivo.

Isso pode ser comprovado dentro da Unesp, pois o documento elaborado pela comissão constituída para definir a política de preservação digital de documentos de arquivo $^{50}$ foi aprovado pelo Conselho Universitário da própria universidade em sessão de 26-04-2018. Cabe destacar também que, seguindo a estratégia do modelo e após a aprovação, foi outorgada e constituída a Comissão Permanente de Preservação Digital ${ }^{51,52}$ com o objetivo de implementar a política. 
Devem ser destacados alguns pontos importantes: 1) na estratégia de criação do modelo, a escolha de se estudar a experiência da Unesp deu-se pela especificidade desta possuir uma estrutura organizacional descentralizada, com múltiplos campus; 2) como a preservação digital envolve aspectos organizacionais, técnicos e legais, a criação de uma equipe multidisciplinar se mostrou fundamental; 3) o apoio dos gestores para o desenvolvimento das atividades da equipe multidisciplinar foi importante; e 4) o entendimento da política de preservação digital como parte do investimento institucional.

O estudo e a escolha de estratégias se mostraram necessários na etapa de criação do modelo. Dados da CADA e de outras comissões internas da Unesp foram de grande utilidade para o debate. Para o andamento dos trabalhos, uma etapa a se destacar foi a criação de um rascunho do documento, que norteou as discussões e a elaboração da proposta final.

Uma vez finalizado o texto relativo à política de preservação digital da instituição, um ponto importante a destacar é a recomendação de que o documento elaborado seja aprovado por instâncias superiores de cada IES, à semelhança do que aconteceu na Unesp. Esse é um cuidado importante para garantir a inserção da preservação digital nos objetivos e na política estratégica da instituição, ocasionando estabilidade mesmo diante das mudanças de gestão, que periodicamente ocorrem nas IES.

Com a disseminação para a comunidade acadêmica do conhecimento adquirido ao longo do processo de elaboração e homologação da política, espera-se contribuir para o estabelecimento de um padrão para o desenvolvimento de políticas de preservação digital de documentos de arquivo em universidades. Nesse sentido, acredita-se que o modelo de política de preservação digital, aqui apresentado, tem alcance maior do que somente se destinar aos documentos de arquivo nato-digitais ou digitalizados da Unesp. Considerando as devidas adaptações, poderá ser igualmente aplicado em outros objetos digitais, assim como em outras instituições.

\section{REFERÊNCIAS}

1. Bizello ML. Reflexões sobre a avaliação de documentos na Universidade Estadual Paulista "Júlio de Mesquita Filho". In: Troitiño S, organizador. Panorama da gestão documental na Unesp. São Paulo: Cultura Acadêmica; 2018. p. 73-81.

2. Boso AK, Sousa RAR, Cisne CS, Coradi JP. Importância do arquivo universitário. Revista ACB. 2007 jan;12(1):123-31.

3. Presidência da República (BR). Casa Civil. Lei no 8.159, de 8 de janeiro de 1991. Dispõe sobre a política nacional de arquivos públicos e privados e dá outras providências. DOU [Internet] 9 jan. 1991 [citado em 2020 maio 16]. Disponível em: http://www.planalto.gov.br/ccivil 03/LEIS/L8159.htm

4. Ministério da Educação (BR). Portaria no 1.224, de 18 de dezembro de 2013. Institui normas sobre a manutenção e guarda do Acervo Acadêmico das Instituições de Educação Superior (IES) pertencentes ao sistema federal de ensino. DOU [Internet] 19 dez 2013 [citado em 2020 maio 16]. Disponível em: https://abmes.org.br/arquivos/legislacoes/Port-1224-2013-12-18.pdf.

5. Arquivo Nacional (BR). Portaria AN/MJ no 92, de 23 de setembro de 2011. Aprova o Código de Classificação e a Tabela de Temporalidade e Destinação de Documentos de Arquivo relativos às Atividades-Fim das Instituições Federais de Ensino Superior (IFES). DOU [Internet] 26 set 2011 [citado em 2020 maio 16]. Disponível em: http://www.siga.arquivonacional.gov.br/index.php/legislacao-enormas/legislacao-portarias/337-portaria-an-mj-n-92-de-23-de-setembro-de-2011.

6. Bellotto HL. Universidade e arquivo: perfil, história e convergência. Transformação. 1989 Set/Dez;1(3):15-28.

7. Universidade Estadual Paulista "Júlio de Mesquita Filho" (BR). Portaria Unesp no 469 de 25 de julho de 2012. Regulamenta a fixação das atribuições das unidades administrativas que integram a estrutura da Unesp. DOESP [Internet] 26 jul 2012 [citado em 2020 maio 16]. Disponível em: https://www.feb.unesp. br/Home/Administracao110/DTAd/home/portaria-469-2012---atribuicoes-administrativas.pdf. 
8. Universidade Estadual Paulista "Júlio de Mesquita Filho" (BR). Resolução Unesp No 62 de 09 de outubro de 2015. Aprova o Plano de Classificação de Documentos e a Tabela de Temporalidade de Documentos da Universidade Estadual Paulista "Júlio de Mesquita Filho": Atividades-Meio. DOESP [Internet] 10 out 2015 [citado em 2020 maio 16]. Disponível em: https://ib.rc.unesp.br/ Home/Instituicao/Administracao/ SecaoTecnicadeComunicacoes/resolucao 62.pdf.

9. Universidade Estadual Paulista "Júlio de Mesquita Filho" (BR). Resolução Unesp No 09, de 08 de fevereiro de 2018. Aprova o Plano de Classificação de Documentos e a Tabela de Temporalidade de Documentos da Universidade Estadual Paulista "Júlio de Mesquita Filho": atividades-fim. DOESP [Internet] 9 fev 2018 [citado em 2020 maio 16]. Disponível em: https://www2.unesp.br/Home/ gabinete ses/resolucao 92018 pg_0110.pdf.

10. Troitiño S, organizador. Panorama da gestão documental na Unesp. São Paulo: Cultura Acadêmica; 2018.

11. Universidade Estadual Paulista "Júlio de Mesquita Filho" (BR). Portaria Unesp no 81 de 01 de março de 2016. Institui a Comissão para fins de elaboração da Política de preservação digital de documentos de arquivo. DOESP [Internet]. 1 mar 2016 [citado em 2016 mar 3]. Disponível em: https://sistemas.unesp. br/legislacaoweb/?base $=P \&$ numero $=81 \& a n o=2016 \&$ dataDocumento $=01 / 03 / 2016$.

12. Cruz-Mundet JR. Diccionário de Archivística. Madrid: Alianza Editorial; 2011.

13. Vásquez MM. Hacia una política archivística. In: Navarro AC. Archivos y documentos: textos seminales. São Paulo: ARQ-SP; 2015. p. 93-113.

14. Sousa RTB. $O$ arquivista e as políticas públicas de arquivo. Anais do $2^{\circ}$ Congresso Nacional de Arquivologia; 2006 23-27 jul; Porto Alegre (RS). Porto Alegre: ABARQ/UnB; 2006. p. 1-15.

15. Driskill M. Archival Policy. In: Duranti L, Franks PC, editores. Encyclopedia of Archival Science. Lanham: Rowman \& Littlefield; 2015; p.70-3.

16. Troitiño S. De interesse público: política de aquisição de acervos como instrumento de preservação de documentos. Revista do Arquivo [Internet]. 2017 [citado em 2020 maio 16];(4). Disponível em: http:// www.arquivoestado.sp.gov.br/revista do arquivo/04/artigo 04.php

17. Fujita MSL, Troitiño S. Política de indexação no contexto da política arquivística de preservação digital do Centro de Documentação e Memória da Unesp. PragMATIZES [Internet]. jun 2019 [citado em 2020 maio 16]:91-110. Disponível em: https://periodicos.uff.br/pragmatizes/ article/view/27982/16804.

18. Fuster Ruiz F. Política archivística e planificación general de los archivos. In: Ruiz-Rodríguez AÁ, editor. Manual de Archivística. Madrid: Editorial Síntesis; 1995. p. 281-324.

19. Duranti L. Archives as a place. Arch Soc Stud. 2007 Mar;1(0):445-66.

20. Grácio JCA. Preservação digital na gestão da informação: um modelo processual para as instituições de ensino superior [Internet]. São Paulo: Cultura Acadêmica; 2012 [citado em 2020 maio 16]. Disponível em: https://repositorio.unesp.br/handle/11449/113727.

21. Ferreira M. Introdução à preservação digital: conceitos, estratégias e actuais consensos [Internet]. Guimarães (Portugal): Escola de Engenharia da Universidade do Minho; 2006 [citado em 2020 maio 16]. Disponível em: https://repositorium.sdum.uminho.pt/bitstream/1822/5820/1/livro.pdf.

22. Arellano MA. Preservação de documentos digitais. CiêncInform [Internet]. 2004 [citado 16 maio 2020]:33(2):15-27. Disponível em: http://www.scielo.br/pdf/ci/v33n2/a02v33n2.pdf.

23. Conselho Nacional de Arquivos (BR). Câmara Técnica de Documentos Eletrônicos. e-ARQ Brasil: modelo de requisitos para sistemas informatizados de gestão arquivística de documentos: Câmara Técnica de Documentos Eletrônicos. 1.1. [Internet] Versão. 2011 [citado em 2020 maio 16]. Disponível em: http:// www.siga.arquivonacional.gov.br/images/publicacoes/e-arq.pdf.

24. Flores D, Rocco BCB, Santos HM. Cadeia de custódia para documentos arquivísticos digitais. Acervo [Internet]. jul/dez 2016 [citado em 2020 maio 16];29(2):117-32.

25. Sierman B, Jones C, Elstrøm G. Scape catalogue of preservation policy elements [Internet]. 2014 [cited 2020 May 16]. Available from: https://scape-project.eu/wp-content/uploads/2014/02/SCAPE D13.2 KB V1.0.pdf.

26. ICA. InterPares: desarrollo de políticas y procedimientos para la preservación digital 2 [Internet]. Traducción al español: Alicia Barnard, Alejandro Delgado y Juan Voutssás. México: Archivo General de la Nación; 2017 [citado em 2020 maio 16]. Disponível em: https://www.gob.mx/cms/uploads/attachment/ file/228990/InterPARES 2 020617.pdf. 
27. Arellano MA, Andrade RS. Preservação digital e os profissionais da informação. DataGramaZero [Internet]. 2006 [citado em 2020 maio 16];7(5). Disponível em: http://www.dgz.org.br/out06/Art 05.htm.

28. Associação Brasileira de Normas Técnicas (BR). NBR 15472:2007: sistemas espaciais de dados e informações: modelo de referência para um sistema aberto de arquivamento de informação (SAAI). Rio de Janeiro; 2007.

29. Presidência da República (BR). Casa Civil. Lei no 12.682, de 9 de julho de 2012. Dispõe sobre a elaboração e o arquivamento de documentos em meios eletromagnéticos. DOU [Internet] 10 jun 2012 [citado em 2020 maio 16]. Disponível em: http://www.planalto.gov.br/ccivil 03/ ato2011-2014/2012/ lei/l12682.htm.

30. Conselho Nacional de Arquivos (BR). Resolução n. 37, de 19 de dezembro de 2012. Aprova as Diretrizes para a Presunção de Autenticidade de Documentos Arquivísticos. DOU [Internet] 12 dez 2012 [citado em 2020 maio 16]. Disponível em: http://conarq.gov.br/resolucoes-do-conarq/279-resolucao-n-37,-de19-de-dezembro-de-2012.html.

31. Conselho Nacional de Arquivos (BR). Resolução n. 43, de 4 de setembro de 2015. Diretrizes para a implementação de Repositórios Arquivísticos Digitais Confiáveis - RDC-Arq. DOU [Internet] 8 set 2015 [citado 16 maio 2020]. Disponível em: http://www.conarq.gov.br/images/publicacoes textos/diretrizes rdc arq.pdf.

32. Arellano MA, Oliveira AF. Gestão de repositórios de preservação digital. Rev Digit Bibliotecon Cienc Inf. [Internet] set/dez 2016 [citado em 2020 maio 16];14(3):465-83. Disponível em: https://periodicos.sbu. unicamp.br/ojs/index.php/rdbci/article/view/8646346.

33. Baggio CC, Flores D. Estratégias, critérios e políticas para preservação de documentos digitais em arquivos. Cienc Inf. [Internet] 2012 maio/dez [citado em 2020 maio 16];41(2-3):58-71. Disponível em: http://revista.ibict.br/ciinf/article/viewFile/1336/1515.

34. Santos HM, Flores D. Repositórios digitais confiáveis para documentos arquivísticos: ponderações sobre a preservação em longo prazo. Perspect Ciênc Inf [Internet]. 2015 [citado 16 maio 2020 citado em 2020 maio 16];20(2):198-218. Disponível em: https://www.scielo.br/pdf/pci/v20n2/1413-9936pci-20-02-00198.pdf.

35. Flores D. Cadeia de custódia dos documentos arquivísticos digitais: do SIGAD ao RDC-Arq. In: Blog do Grupo CNPq UFF Ged/A, Patrimônio Documental Documentos Arquivísticos. Brasília (DF); 16 jun 2016 [citado em 2020 maio 16]. Disponível em: http://documentosdigitais.blogspot. com.

36. Sayão LF. Uma outra face dos metadados: informações para a gestão da preservação digital. Encontros Bibli [Internet]. 2010 [citado em 2020 maio 16];15(30):1-31. Disponível em: https://periodicos.ufsc.br/ index.php/eb/article/view/1518-2924.2010v15n30p1.

37. Arellano MA. Cariniana: uma rede nacional de preservação digital. Cienc Inf [Internet]. jan/abr 2012 [citado em 2020 maio 16];41(1):83-91. Disponível em: http://revista.ibict.br/ciinf/article/ download/1354/1533.

38. InterPARES org [Internet] (CAN). The International Research on Permanent Authentic Records in Electronic Systems [Internet]; 1999 [cited 2020 May 16]. Available from: http://www.interpares.org/.

39. Rezende LVR, Cruz-Riascos AS, Hott DFM. Em busca de repositórios digitais confiáveis no Brasil: análise da infraestrutura organizacional conforme a norma ISO 16363/2012. Reciis [Internet]. Nov 2017 [citado em 2020 maio 16];11(Supl). Disponível em: https://www.reciis.icict.fiocruz.br/index.php/reciis/article/ view/1390.

40. Sheldon M. Analysis of current digital preservation policies: archives, libraries, and museums [Internet]. Library of Congress/ National Digital Information Infrastructure and Preservation Program (NDIIPP); 2013. [cited 2020 May 16]. Available from: http://www.digitalpreservation.gov/documents/Analysis\%20 of\%20Current\%20Digital\%20Preservation\%20Policiecs.pdf.

41. Universidade Estadual de Campinas (BR). Resolução GR-017/2011 de 29/06/2011. Estabelece diretrizes e define procedimentos para a gestão, a preservação e o acesso contínuo aos documentos arquivísticos digitais da Universidade Estadual de Campinas. DOESP [Internet]. 1 jul 2011 [citado em 2020 maio 16]. Disponível em: https://www.pg.unicamp.br/mostra norma.php?id norma=3057.

42. Câmara dos Deputados (BR). Ato da mesa no 48 de 16 jun 2012. Institui a Política de Preservação Digital da Câmara dos Deputados. [Internet] 2012 [citado em 2017 jan 4]. Disponível em: https:// www2.camara.leg.br/legin/int/atomes/2012/atodamesa-48-16-julho-2012-773828-normaatualizada-cdmesa.pdf. 
43. Arquivo Nacional (BR). AN Digital - Política de Preservação Digital. Versão 1 [Internet]. 2012 [citado 16 maio 2020]. Disponível em: http://siga.arquivonacional.gov.br/images/an digital/and_politica_ preservacao digital v1.pdf.

44. 44 Queensland (AUS). Digital preservation policy at State Library of Queensland [Internet]; 2008 [cited 2020 May 16]. Available from: www.slq.qld.gov.au.

45. Parliamentary Archives (GBR). A digital preservation policy for parliament. [Internet]; 2009 [cited 2020 May 16]. Available from: https://www.parliament.uk/documents/upload/ digitalpreservationpolicy1.0.pdf.

46. Banach M, Shepherd K, Rubinstein A, Shelburne B, Canavan MJ, Yuan L. University of Massachusetts Amherst Libraries Digital Preservation Policy [Internet]; 2011 [cited 2020 May 16]. Available from: file:///C:/Users/User/Downloads/University-of-Massachusetts-Amherst-Libraries-Digital-PreservationPolicy4-26-2013-templated\%20(2).pdf.

47. National Library of Australia (AUS). Digital Preservation Policy [Internet]. 4th edition; 2013 [cited 2020 May 16]. Available from: https://www.nla.gov.au/policy-and-planning/digital-preservation-policy.

48. Yale University Library (EUA). Yale University Library's Digital Preservation Policy Framework [Internet]; 2014 [cited 2020 May 16]. Available from:https://guides.library.yale.edu/ld.php? content id=26251943.

49. Silva Junior LP, Borges MM. Preservação digital no Repositório Científico de Acesso Aberto de Portugal. Rev Eletron de Comun Inf Inov Saúde - Reciis [Internet]. out/dez 2014 [citado em 2020 maio 16];8(4):567-74. Disponível em: http://www.reciis.icict.fiocruz.br/index.php/reciis/article/ view/911.

50. Universidade Estadual Paulista "Júlio de Mesquita Filho" (BR). Política de preservação digital para documentos de arquivo da Unesp [Internet]; São Paulo; 2017 [citado em 2018 jun 9]. Disponível em: https://www2.unesp.br/Home/cppd/politica-de-preservacao-digital--para-documentos-de-arquivo-daunesp---v-1.0.pdf.

51. Universidade Estadual Paulista "Júlio de Mesquita Filho" (BR). Portaria Unesp no 213 de 8 de junho de 2018. Dispõe sobre a criação e competências da Comissão Permanente de Preservação Digital da Unesp. DOESP [Internet]. 9 jun 2018 [citado em 2018 jun 9]. Disponível em:https://www2.unesp.br/Home/ cppd/portaria unesp 213 de 08-06-2018.pdf.

52. Universidade Estadual Paulista "Júlio de Mesquita Filho" (BR). Portaria Unesp no 214 de 08 de junho de 2018. Dispõe sobre a composição da Comissão Permanente de Preservação Digital da Unesp. DOESP [Internet]. 8 jun 2018 [citado em 2018 jun 9]. Disponível em: https://www2.unesp.br/Home/cppd/ portaria unesp 214 de 08-06-2018.pdf. 